Article

\title{
Outdoor Air-Cooling System for a Computer Room and Its Corresponding Energy-Saving Effect
}

\author{
JiHyun Hwang and Taewon Lee * \\ Korea Institute of Civil Engineering and Building Technology, Goyang-si 10223, Gyeonggido, Korea; \\ flyhigh0316@kict.re.kr \\ * Correspondence: twlee@kict.re.kr; Tel.: +82-10-3088-9605
}

Received: 7 July 2020; Accepted: 20 October 2020; Published: 2 November 2020

\begin{abstract}
The recent expansion of the internet network and rapid advancements in information and communication technology are expected to lead to a significant increase in power consumption and the number of data centers. However, these data centers consume a considerable amount of electric power all year round, regardless of working days or holidays; thus, energy saving at these facilities has become essential. A disproportionate level of power consumption is concentrated in computer rooms because air conditioners in these rooms are required to operate throughout the year to maintain a constant indoor environment for stable operation of computer equipment with high-heat release densities. Considerable energy-saving potential is expected in such computer rooms, which consume high levels of energy, if an outdoor air-cooling system and air conditioners are installed. These systems can reduce the indoor space temperature by introducing a relatively low outdoor air temperature. Therefore, we studied the energy-saving effect of introducing an outdoor air-cooling system in a computer room with a disorganized arrangement of servers and an inadequate air conditioning system in a research complex in Korea. The findings of this study confirmed that annual energy savings of up to approximately $40 \%$ can be achieved.
\end{abstract}

Keywords: computer room; outdoor air-cooling system; energy saving; field application

\section{Introduction}

In 2018, there were 145 data centers [1] in Korea. The annual power consumption in these data centers in 2016 was approximately 2.8 billion $\mathrm{kWh}$, representing $1 \%$ of the industrial power consumption of 280 billion $\mathrm{kWh}$ [2]. Moreover, the number of data centers and the associated power consumption are expected to increase significantly because of the expansion of the internet and the rapid development of information and communication technology.

According to the results of a power consumption analysis performed in a research complex in Korea, more than $15 \%$ of the annual power consumed in the complex, which consisted of 20 buildings, occurred in the computer room. Particularly in the computer room, for the baseload time zones such as midnight, the power consumed is $98 \%$ in the summer, $99.1 \%$ in the mid-season, $98.7 \%$ in the winter, and $99 \%$ during holidays, regardless of the season, indicating that a significant amount of electric energy is consumed throughout the year, regardless of weekdays or weekends [3,4]. This disproportionate amount of power consumption is concentrated in the computer room because the air conditioners operate throughout the year to maintain a constant indoor environment for stable operation of the computer equipment with a high-heat release density. Thus, there is significant room for improvement in terms of energy saving. In other words, if an outdoor air-cooling system and air conditioners are installed to cool the indoor space by introducing a relatively low outdoor air temperature, a considerable degree of energy saving is expected in a computer room with high-energy consumption. 
A survey of the relevant literature shows that Soe et al. [5] conducted an energy simulation and reported that the energy consumption was reduced by approximately $49 \%$ when an outdoor air-cooling system was used. Chang et al. [6] proposed a multi-outdoor air-cooling system (outdoor air-cooling water + outdoor air cooling) and discussed the manner in which $26.7 \%$ of energy can be saved upon examining the energy-saving effect through energy simulation. Jeong et al. [7] analyzed the annual energy consumption achieved via each control technique through energy simulations and confirmed that the enthalpy control technique yielded the best performance, with an energy-saving rate of $54.5 \%$, compared with that of the conventional technique. Jung et al. [8] examined the effect of a multi-outdoor air cooling system (outdoor air-cooling water + outdoor air cooling + variable air volume) through experiments, and their analysis showed that the annual energy cost was reduced by approximately $44.72 \%$ through an energy simulation program. The above examples show that studies have been conducted on the prediction and analysis of energy saving in the design of an outdoor air-cooling system for a computer room and improvement of these facilities. In contrast, very few studies have investigated its effective design, operation method, and energy-saving effect using an actual field application. In this study, we investigated the energy-saving effect of introducing an outdoor air-cooling system in the computer room of a research complex in Korea with a disorganized arrangement of servers and inadequate air conditioning system. The results confirmed that approximately $40 \%$ of annual energy savings can be achieved.

\section{Application Site and System Installation}

\subsection{Test-Bed Model}

Figure 1 shows the layout specifications and a photograph of the operation site of the computer room in Korea, selected as the analysis model for this study. The room area is $156.48 \mathrm{~m}^{2}$, and its height is $2.97 \mathrm{~m}$. Moreover, the target space faces the outdoor air in the north and east, whereas the space in contact with the adjacent space that is air-conditioned faces the south and west side. The number of server racks is 32 , and the heat release rate according to the operation of the computer equipment is approximately $40 \mathrm{~kW}$. Table 1 summarizes the detailed specifications of the computer room selected as the demonstration model.

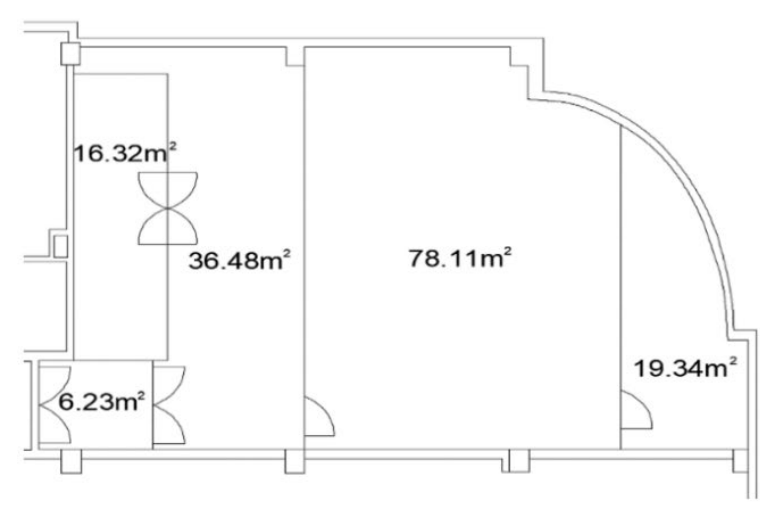

(a)

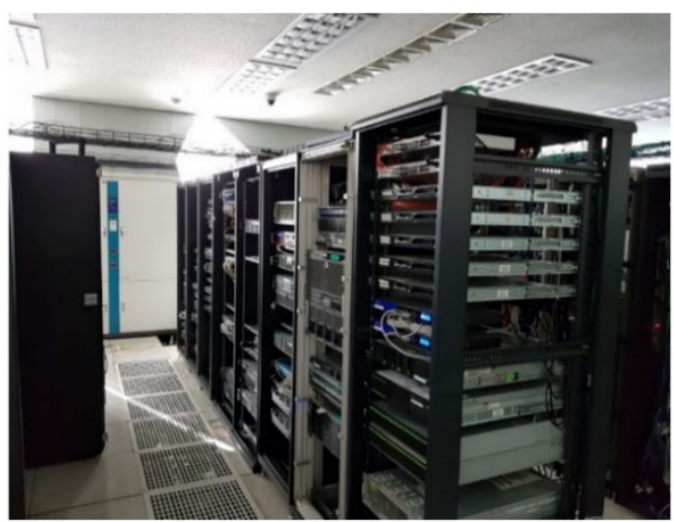

(b)

Figure 1. Model of the computer room considered in this study: (a) layout of the room; (b) photograph of the computer room. 
Table 1. Specifications of the computer room and servers.

\begin{tabular}{ccc}
\hline Test Bed & Servers & Facilities \\
\hline Site: Koyang, Kyeonggi & & \\
Floor area: $156.48 \mathrm{~m}^{2}$ & Number of racks: $32(600 \times 1000 \times 2000)$ & Air conditioner: $15 \mathrm{RT}$ Dual $\times 2$ \\
Height: $2.97 \mathrm{~m}$ & Heat release rate from servers: $40 \mathrm{~kW}$ & SA Fan Air volume: $19,800 \mathrm{~m}^{3} / \mathrm{h}$ \\
Heat transmission rate wall: $0.48 \mathrm{~W} /\left(\mathrm{m}^{2} .{ }^{\circ} \mathrm{C}\right)$ & (Estimated) & \\
Heat transmission rate window: $3.3 \mathrm{~W} /\left(\mathrm{m}^{2} \cdot{ }^{\circ} \mathrm{C}\right)$ & & \\
\hline
\end{tabular}

\subsection{On-Site Installation and Operation}

When the operating status of the existing computer room was analyzed, the cooling effect of the server was observed to be considerably reduced because of the inefficient server layout that blocked heat circulation. Although the temperature of the air conditioner was set to $22 \pm 2{ }^{\circ} \mathrm{C}$, the actual indoor temperature range seemed to be non-uniform and poor at approximately $26-31^{\circ} \mathrm{C}$. Therefore, in this study, the server racks in the computer room were rearranged by dividing them into highand low-temperature areas for efficient facility operation, as shown in Figure 2. The conventional top discharge cooling method was changed to the bottom discharge cooling method through the supply/exhaust duct in the high-temperature area, as shown in Figure 2. These changes resulted in an indoor temperature of $21-26^{\circ} \mathrm{C}$, which is acceptable. As described in the previous section, the indoor temperature and humidity conditions were set to $24^{\circ} \mathrm{C}$ and $40-60 \%$, respectively. Table 2 presents a comparison of the results before and after improving the computer room facilities and operation.
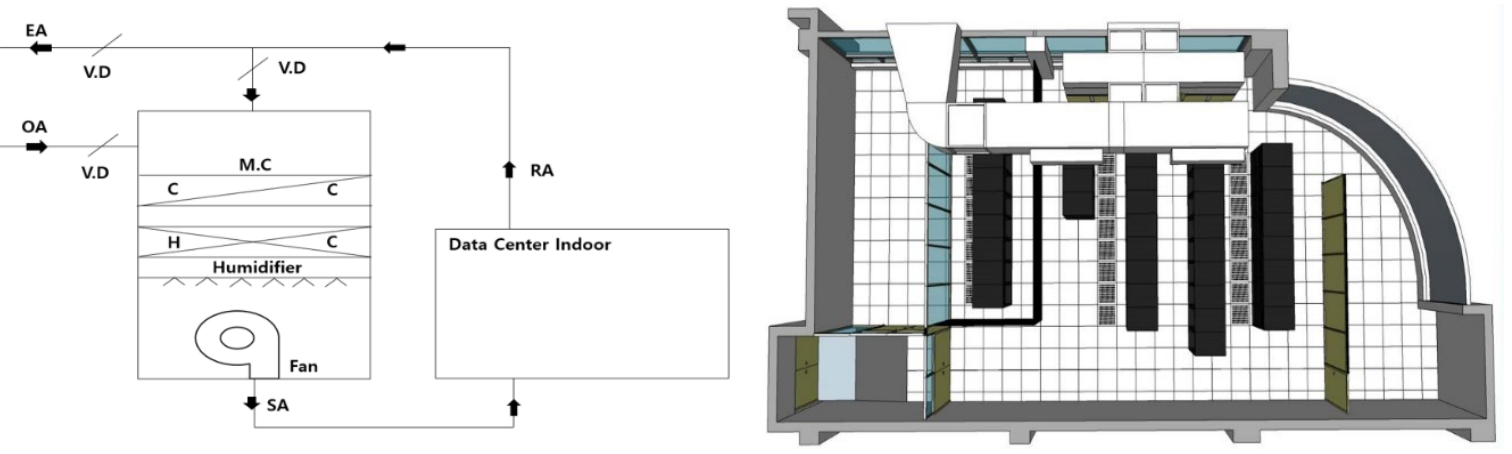

Figure 2. Schematic diagram and Floor plan of the outdoor air-cooling system.

Table 2. Comparison of indoor conditions before and after the improvements.

\begin{tabular}{ccc}
\hline & Before & After \\
\hline Operating set condition & $22{ }^{\circ} \mathrm{C} \pm 2{ }^{\circ} \mathrm{C} \mathrm{DB}$, & $24{ }^{\circ} \mathrm{C}+1{ }^{\circ} \mathrm{C} \mathrm{DB}$, \\
Temperature range & $50 \% \pm 5 \% \mathrm{RH}$ & $40-60 \% \mathrm{RH}$ \\
\hline
\end{tabular}

Furthermore, as shown in Figure 3, the existing all-air recirculation cooling method employed by the air conditioner was improved, and additional air supply, exhaust, and outdoor air dampers were provided to establish an outdoor air-cooling system capable of controlling the air volume introduced by it. Figure 3a shows the all-air recirculation cooling method; if the outdoor air temperature is higher than a certain level considering the indoor setting temperature, cooling through outdoor air introduction is not possible. Therefore, the outdoor air is blocked, and cooling is achieved using only the air conditioner. Figure $3 \mathrm{~b}$ shows the method employed to stop the air conditioner when the outdoor air temperature falls below the indoor setting temperature and to perform cooling using only outdoor air. Figure $3 \mathrm{c}$ displays the mixed operation method used to supply air at the required temperature by mixing air recovered from the relatively hot indoor space when the outdoor air temperature is very low (e.g., during the winter). 


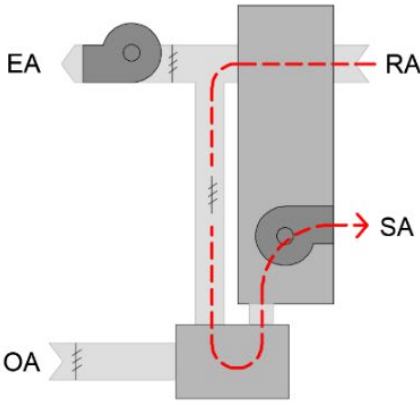

(a)

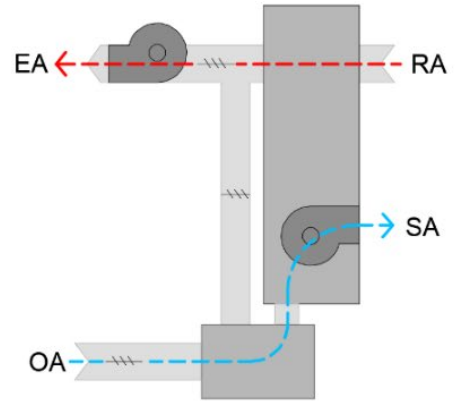

(b)

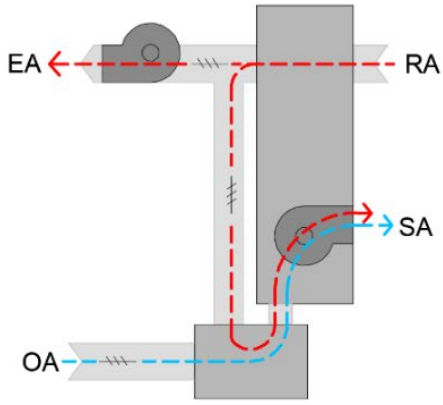

(c)

Figure 3. Operating method of the cooling system for the computer room: (a) All-air recirculation; (b) outdoor air cooling; (c) mixed type.

Table 3 lists the specifications of the outdoor air-cooling system installed at the experimental site. The outdoor air-cooling system was constructed by installing an exhaust fan and an inverter to adjust the air volume as required in an existing facility comprising two air conditioners with a capacity of 15 RT. For air supply, the air supply fan of the existing air conditioner was used to save cost and installation space. The total air volume moved by the air supply fan and the exhaust fan was $19,800 \mathrm{~m}^{3} / \mathrm{h}$. The air supply fan uses a constant air volume method, whereas the exhaust fan adopts a variable air volume method by inverter control.

Table 3. Details of the installed outdoor air cooling system.

\begin{tabular}{ccc}
\hline Equipment & $\begin{array}{c}\text { Fan Air Volume } \\
\left(\mathbf{m}^{\mathbf{3}} \mathbf{h}\right)\end{array}$ & $\begin{array}{c}\text { Electricity Consumption } \\
\mathbf{( k W )}\end{array}$ \\
\hline SA Fan & $9900 \times 1 \mathrm{EA}$ & $3.2 \times 2 \mathrm{EA}$ \\
Compressor & - & $7.2 \times 4 \mathrm{EA}$ \\
EA Fan, Inverter & $19,800 \times 1 \mathrm{EA}$ & $4.7 \times 1 \mathrm{EA}$ \\
\hline
\end{tabular}

Figure 4 shows the control screen built for real-time monitoring of the facilities at the site. The screen allows the collection and subsequent analysis of data regarding the temperature and humidity of the indoor- and outdoor-returning air, the temperature at the exhaust, high and low temperature in the computer room, inverter output value, and the fan and air conditioner power consumption. For this study, the temperature and humidity data from the TC thermometer and air conditioner were used. The measurement cycle of the equipment is every one minute.

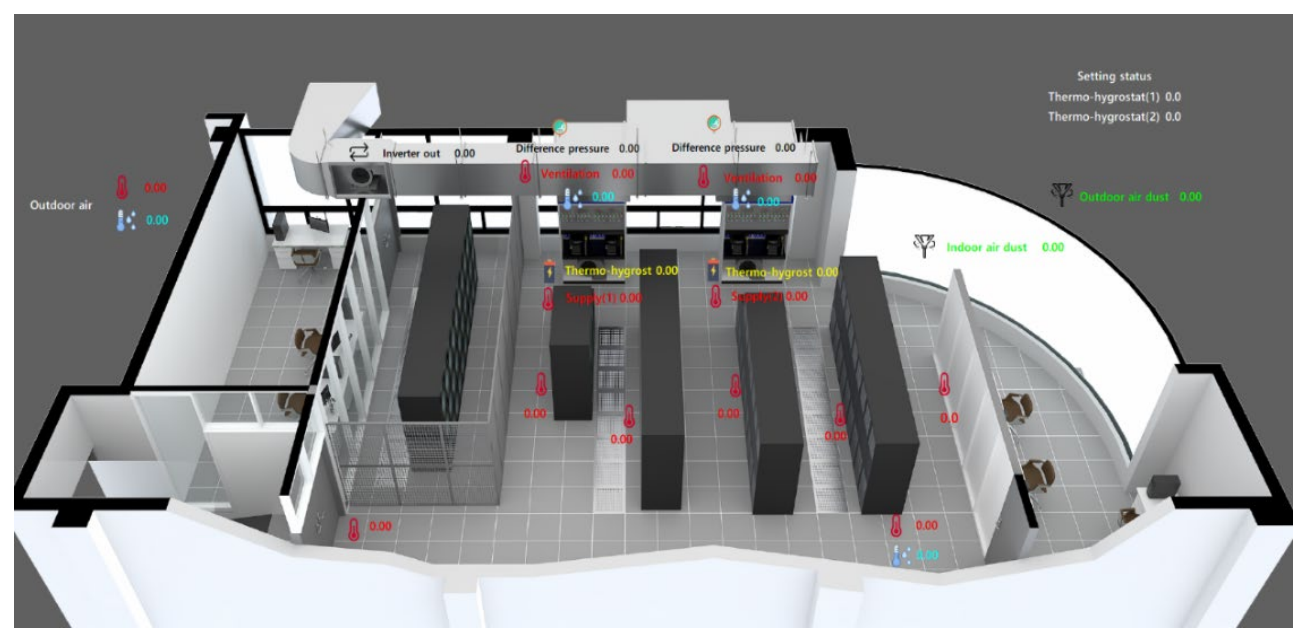

Figure 4. View of the monitoring screen for the outdoor air cooling system. 


\section{Results and Discussion}

\subsection{Analysis of Operation Results}

Figure 5 shows the result of the outdoor air-cooling system introduced in the computer room for the field application. The figure illustrates the temperature and humidity of the outdoor and indoor air, that is, the return air. Moreover, the figure shows the temperature range of the supply air, cool zone, and hot zone on a typical day when outdoor air cooling can be performed. It also shows the operating range of the outdoor air-cooling system.

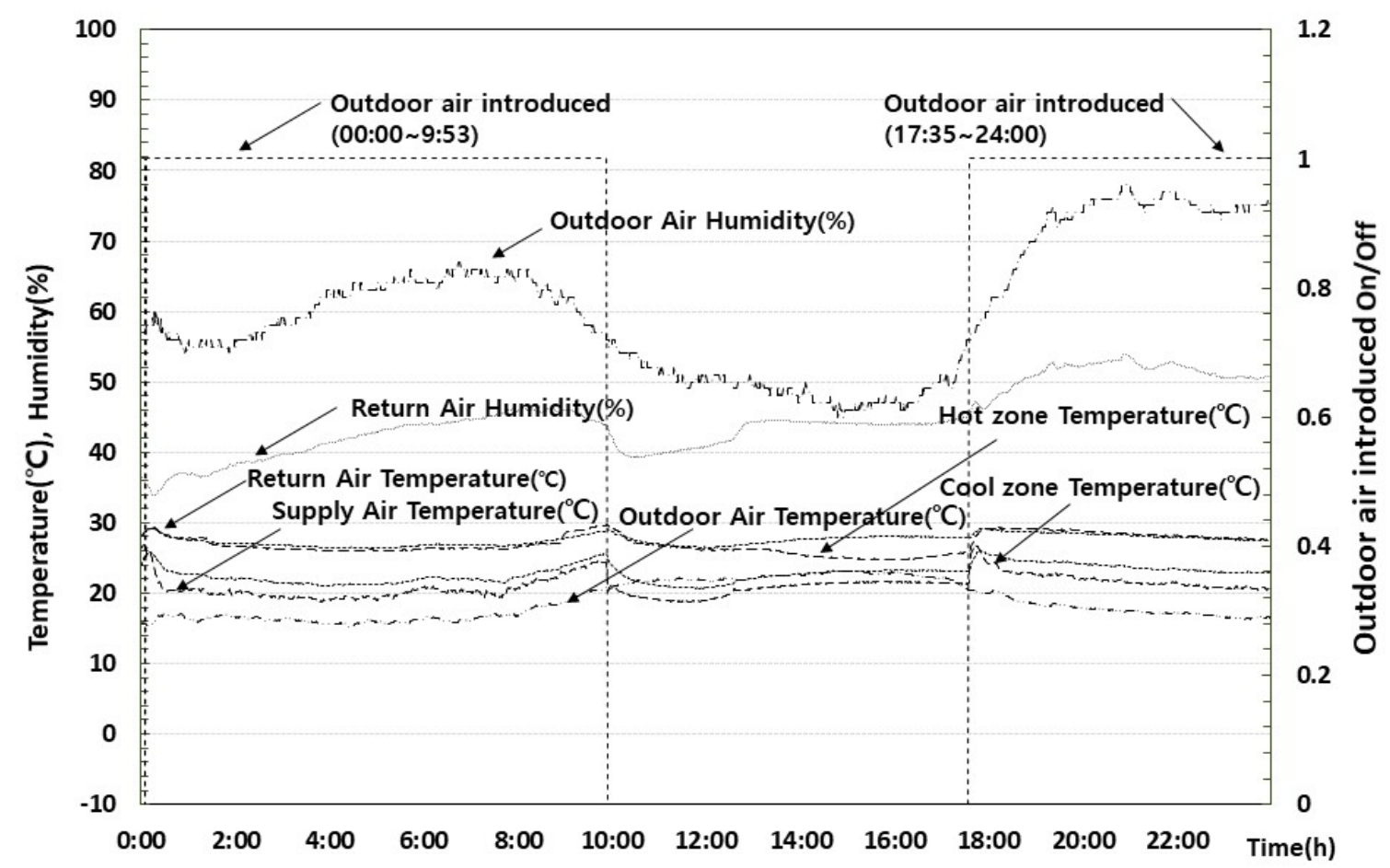

Figure 5. Time variation of indoor and outdoor air conditions at the test computer room for a typical day.

First, the temperature and humidity of the outdoor air showed a typical daily pattern over time. The supply air temperature was proportional to the temperature change of the outdoor air during the period of outdoor air cooling; however, the supply air temperature showed a slightly higher value than the outdoor air temperature, which is considered to be as a result of the heat released from the fan. Moreover, the cool zone had a slightly higher temperature than that of the supply air, whereas the hot zone had almost the same temperature as that of the return air. When the cooling method changed from outdoor air cooling to AC cooling using the air conditioner, and from AC cooling to outdoor air cooling, the temperature range in the computer room showed a discontinuous pattern. This is assumed to be because, for AC cooling, a relatively constant temperature can be maintained by an air conditioner. However, for outdoor air cooling, the temperature range in the computer room increased overall when it changed from outdoor air cooling to AC cooling or vice versa, owing to outdoor air effects. Furthermore, the humidity of the return air was maintained at a lower value than that of the outdoor air because of the heat generated by the computer equipment.

However, after approximately 9:53, outdoor air cooling was no longer possible because of the increase in the outdoor air temperature, and the air conditioner was operated. During this period, the temperature range in the computer room decreased in the early stage of switching to AC cooling, as described above; however, the temperature remained constant afterward. The outdoor air temperature decreased, and after 17:35, AC cooling stopped, and outdoor air cooling started. 
Figure 6 shows a comparison of the results of outdoor air cooling and cooling via only the air conditioner on the day in which the climatic conditions were similar to those of the day before the facility improvement was conducted (an average daily outdoor air temperature of $18.8^{\circ} \mathrm{C}$ and a relative humidity of $60.3 \%$ ). Moreover, the figure shows the daily power consumption for each case. It depicts the case before the facility improvement in which only air conditioners were used for cooling and illustrates that cooling was performed through periodic control of multiple compressors. However, when outdoor air cooling was introduced, the power consumption was significantly decreased by performing outdoor air cooling, except for the case where the outdoor air temperature was above a certain level, as described above.

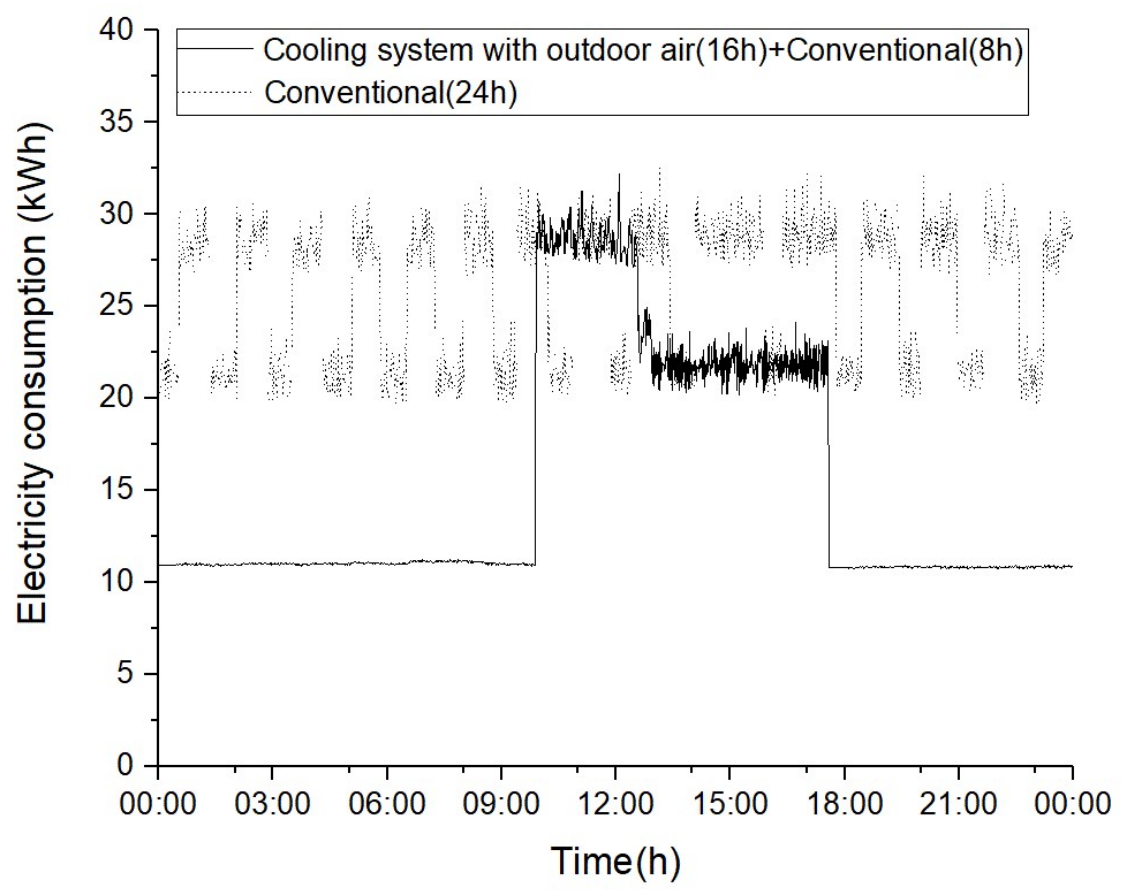

Figure 6. Comparison of the daily electric power consumption of the conventional and the proposed cooling method.

When only AC cooling was performed, three compressors with a capacity of $7.2 \mathrm{~kW}$ and two air supply fans with a capacity of $3.2 \mathrm{~kW}$ consumed $28 \mathrm{~kW}$ to operate the air conditioner. In contrast, when operating with outdoor air cooling, two air supply fans with a capacity of $3.2 \mathrm{~kW}$ and one exhaust fan with a capacity of $4.7 \mathrm{~kW}$ consumed a total of $11.1 \mathrm{~kW}$. Details of the energy-saving effect are described later.

Moreover, it can be observed from the figure that the outdoor air cooling system was operated for $16 \mathrm{~h}$ and $18 \mathrm{~min}$ in the early morning, morning (00:00-9:53), and evening (17:35-24:00), when the outdoor air temperature is $20.6{ }^{\circ} \mathrm{C}$ or less. As described above, from the theoretical analysis of the computer room, the outdoor air temperature capable of outdoor air cooling based on the given indoor setting temperature was $19.8^{\circ} \mathrm{C}$ or less. However, in an actual field operation, the outdoor air temperature was $20.6^{\circ} \mathrm{C}$ or less when the outdoor air cooling began to operate. This indicates a difference of only $+0.8^{\circ} \mathrm{C}$ compared with the theoretical analysis result, demonstrating that a relatively accurate prediction is possible.

Table 4 comparatively summarizes the indoor environment and the power consumption with respect to the cooling achieved via the existing method using only the air conditioner and the new method that introduces the outdoor air-cooling system. The indoor setting temperature was set to $22 \pm 2{ }^{\circ} \mathrm{C}$ when only the air conditioner was used. In contrast, when the outdoor air-cooling system was introduced, the indoor setting temperature was increased to $24+1^{\circ} \mathrm{C}$. However, the indoor average temperature in the computer room was reduced from $27.6^{\circ} \mathrm{C}$ to $26.1^{\circ} \mathrm{C}$, representing a decrease of 
$1.5^{\circ} \mathrm{C}$. The temperature range in the indoor space was uniform through rearrangement of the computer equipment, air supply, and exhaust. Therefore, with the indoor setting temperature adjusted to a higher value, the cooling energy consumption was expected to decrease significantly. Moreover, the daily power consumption was $664 \mathrm{kWh}$ when only the air conditioner was used; in contrast, when the outdoor air cooling system was introduced, the power consumption decreased to $363 \mathrm{kWh}$, indicating a power saving of more than $45 \%$.

Table 4. Comparison of the indoor conditions and daily electric power consumption of the conventional and the proposed cooling method.

\begin{tabular}{ccc}
\hline & Conventional & Outdoor Air Introduced \\
\hline Indoor setting condition & $22{ }^{\circ} \mathrm{C} \pm 2{ }^{\circ} \mathrm{C} \mathrm{DB}$, & $24{ }^{\circ} \mathrm{C}+1{ }^{\circ} \mathrm{C} \mathrm{DB}$, \\
Averaged indoor temperature $\left({ }^{\circ} \mathrm{C}\right)$ & $50 \% \pm 5 \% \mathrm{RH}$ & $40-60 \% \mathrm{RH}$ \\
Electric power consumption $(\mathrm{kWh} /$ day) & 27.6 & 26.1 \\
\hline
\end{tabular}

\subsection{Energy-Saving Effect Analysis}

In terms of field application, Figure 7 shows the daily power consumption upon operation of the computer room using the existing air conditioner for a specific period (January 2016-December 2016) prior to the introduction of the outdoor air-cooling system. The figure also shows the measured power consumption upon operation of the newly introduced outdoor air cooling system for a specific period (May 2017-April 2018) according to the daily outdoor average temperature. In the area where the daily average outdoor air temperature is low, no significant difference in the daily power consumption was found. However, as expected, when the daily average outdoor air temperature was above a certain level, for instance, above $5{ }^{\circ} \mathrm{C}$, the power consumption increased with the increase in the cooling load. Moreover, the comparison between the outdoor air cooling and the existing method using only air conditioners revealed that the overall power consumption was significantly reduced. Even if the environment improvement effect described above was not considered, a relatively lower amount of energy was consumed for the same purpose, indicating that the outdoor air cooling system was considerably energy efficient.

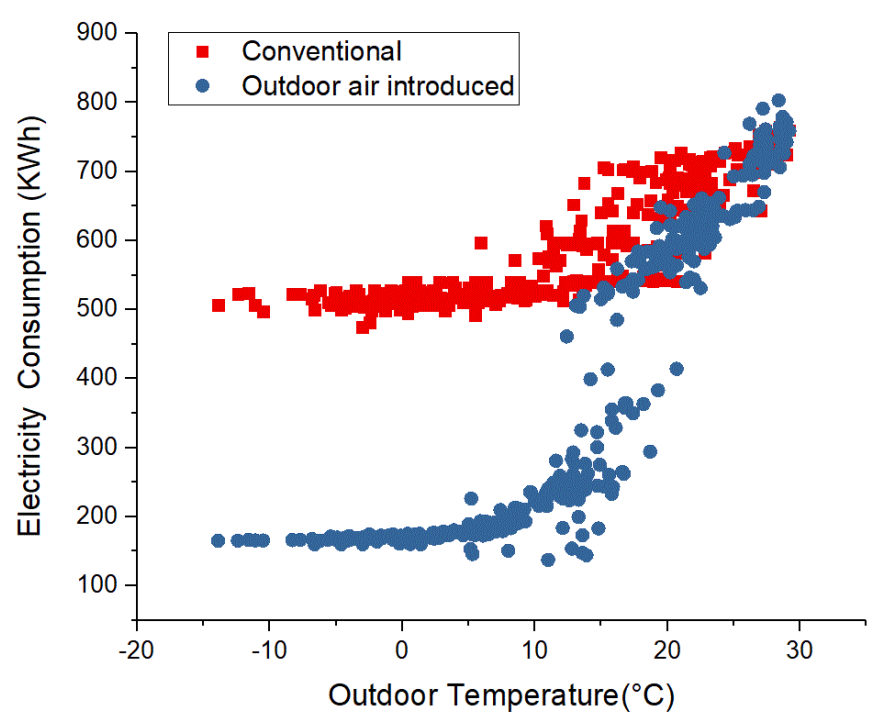

Figure 7. Comparison of the daily electric power consumption according to the daily average outdoor air temperature and the cooling method.

In the winter, when the daily average outdoor air temperature is low, for instance, in the zone below $10{ }^{\circ} \mathrm{C}$, the method employing outdoor air cooling showed that it is possible to reduce the 
power consumption by as much as $66 \%$ compared with that yielded via the conventional method. In this period, because the air conditioner was not operated at all and only outdoor air cooling was used, this ratio can be regarded as the ratio of the power consumption of the outdoor air introduction cooling method to that of the existing method. As the daily average outdoor air temperature increased, the saving effect decreased with increasing fan power consumption for outdoor air cooling and partial operation of the air conditioner for a certain period. However, even during the mid-season with temperatures of $10-20{ }^{\circ} \mathrm{C}$, a saving of approximately $37 \%$ was achieved, and a saving of $6 \%$ was also realized during summer for temperatures of $20^{\circ} \mathrm{C}$ or higher.

Figure 8 shows the same case presented in the previous figure; that is, the power consumption obtained by operating the existing air conditioner before the introduction of the outdoor air cooling system (January 2016-December 2016) and the measured power consumption after the introduction of the outdoor air cooling system (May 2017-April 2018). The results were compared and illustrated monthly. As described above, the figure shows an energy saving of approximately $66 \%$ in the winter from November to February, approximately $37 \%$ in the mid-season from March to May and from September to October, and approximately $6 \%$ in the summer from June to August. In summary, an annual energy saving of up to $40 \%$ could be realized. Additionally, given that outdoor air cooling was not performed because of the circumstances in May and September when the operation was possible, it is expected that the energy-saving effect will increase further.

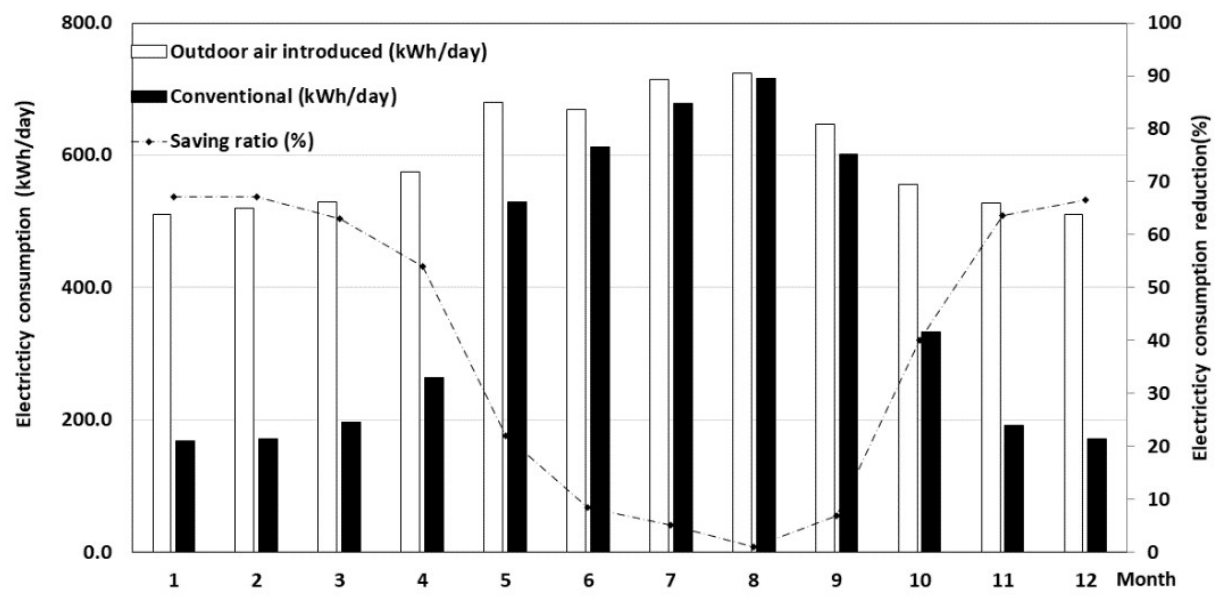

Figure 8. Comparison of monthly electric power consumption and saving ratio by the cooling method.

\section{Conclusions}

Very few studies have investigated the effective design, operation method, and energy-saving effect of using an outdoor cooling system for actual field applications. In this study, the following results were obtained with the installation of an outdoor air-cooling system for a computer room in a research complex that consumes a considerable amount of energy during operation.

1. Efficient arrangement of the computer equipment, supply, and exhaust vents produce a uniform temperature range in the indoor space to increase the indoor setting temperature, reducing the energy consumption for cooling. In this study, although the set temperature in the computer room was increased by $2{ }^{\circ} \mathrm{C}$, the average indoor temperature was reduced by $1.5^{\circ} \mathrm{C}$, improving the indoor environment and saving energy.

2. A comparison of the power consumption of the existing computer room cooling method using only air conditioners and the proposed method shows that introducing the outdoor air cooling system yielded approximately $66 \%$ energy saving in the winter from November to February, $37 \%$ in the mid-season from March to May and from September to October, and 6\% in the summer from June to August. Consequently, energy savings of approximately $40 \%$ or more per year can be achieved. 
Author Contributions: Conceptualization, T.L.; Data curation, J.H.; Formal analysis, J.H.; Funding acquisition, J.H.; Investigation, J.H.; Methodology, J.H.; Project administration, T.L.; Resources, J.H.; Software, J.H.; Supervision, T.L.; Validation, J.H.; Visualization, J.H.; Writing—original draft, J.H.; Writing—review and editing, T.L. All authors have read and agreed to the published version of the manuscript.

Funding: This research was funded by the Ministry of Land, Infrastructure, and Transport; the project was carried out with the support of the Urban Architecture Research Project, grant number 20AUDP-B099686-06.

Conflicts of Interest: The authors declare no conflict of interest. The funders had no role in the design of the study; in the collection, analyses, or interpretation of data; in the writing of the manuscript, or in the decision to publish the results.

\section{Abbreviations}

SA Supply air volume $\left(\mathrm{m}^{3} / \mathrm{h}\right)$

EA Exhaust air volume $\left(\mathrm{m}^{3} / \mathrm{h}\right)$

RA Return air volume $\left(\mathrm{m}^{3} / \mathrm{h}\right)$

OA Outdoor air volume $\left(\mathrm{m}^{3} / \mathrm{h}\right)$

\section{References}

1. Seok, D.K. Summer in the Data Center Must Be Cold. Daily Today News, 2018.

2. Song, J.H.; Song, M.H.; Park, H.B.; Jang, S.H. A Study on Realities of Actual Conditions for the Activation of Data Center Industry Ecosystem; Korea IT Services Industry Association: Seoul, Korea, 2018.

3. Song, J.H.; Moon, H.Y.; Park, H.B. A Foundation Research for the Data, Center Industry Development; Korea IT Services Industry Association: Seoul, Korea, 2015.

4. Lee, T.W. Power consumption analysis and reduction methods for EPMS. Korean Inst. Archit. Sustain. Environ. Build. Syst. 2015, 9, 48-56.

5. Seo, J.H.; Park, S.H. A study on the application of air-side economizer system for the data center. Korean Sol. Energy Soc. 2013, 33, 150-153.

6. Jang, H.J.; Chang, H.J.; Jung, Y.H. Study on the development of energy conservation system for data center by utilizing multi-staged outdoor air cooling. Archit. Inst. Korea 2014, 34, 267-268.

7. Jeong, J.W.; Ham, S.W.; Kim, M.H. A study of direct air-side economizer control strategies for a modular data center. Archit. Inst. Korea 2014, 34, 243-244.

8. Jang, H.J.; Kim, J.Y.; Park, M.G. Development of Cooling System for Reducing Energy Consumption Rates onto $50 \%$ in a Data Center; Ministry of Land, Infrastructure, Transport and Tourism Report; Ministry of Land, Infrastructure, Transport and Tourism: Tokyo, Japan, 2014; pp. 1-213.

Publisher's Note: MDPI stays neutral with regard to jurisdictional claims in published maps and institutional affiliations.

(C) 2020 by the authors. Licensee MDPI, Basel, Switzerland. This article is an open access article distributed under the terms and conditions of the Creative Commons Attribution (CC BY) license (http://creativecommons.org/licenses/by/4.0/). 